\title{
EL MINISTERIO DE LOS LAICOS EN LA IGLESIA
}

DOI: https://doi.org/10.52039/seminarios.v64i224.41

DARIO VITALI*

Tratar la cuestión de los ministerios laicales en la Iglesia no es sencillo. La dificultad radica principalmente en el contexto eclesial: por una parte, se da mucha relevancia a la teología de los laicos, pero, por otra, no se termina de ver qué espacio real ocupan los laicos en la Iglesia. Se habla de «Iglesia toda ella ministerial», pero más allá de la afirmación, que podría sonar como un eslogan, las funciones eclesiales propias de los laicos no parecen tener una importancia concreta. Esto no se debe únicamente a una especie de resistencia del clero para defender su posición de dominio conseguida tras largos siglos de funcionamiento de una Iglesia piramidal, en la que la jerarquía ha acaparado todas las funciones activas. El problema viene también de la falta de claridad en el tema, a menudo utilizada por posiciones ideológicas que ciertamente no favorecen la promoción de una presencia laical, reivindicada a menudo en términos de alternativa al ministerio ordenado.

Aun procurando prescindir del lastre ideológico, no resulta fácil abordar el tema. Se entrecruzan en él muchos elementos, y su complejidad se percibe en cuanto se intenta aclarar los términos del discurso. Hablar de los ministerios de los laicos en la Iglesia requiere articular tres elementos -ministerios, laicos, Iglesia- que forman un sistema. ¿Cómo hacerlo? ¿Por dónde empezar? Más allá de abstracciones, es obvio que el resultado no será el mismo si se parte de los ministerios, de los laicos o de la Iglesia. «Ministerios», «ministerio», «ministerialidad» pertenecen a una familia semántica sobre la cual se ha reflexionado ampliamente en la Iglesia, hasta ahora prescindiendo de los laicos y centrándose en el ministerio ordenado. Ahora bien, los laicos son sujetos en la Iglesia cuya presencia y papel no se reduce a los ministerios que desempeñan. Por lo que se refiere a la Iglesia, es de justicia reconocer que no existe una eclesiología compartida por todos. Más allá de la coincidencia en la eclesiología de comunión, las

* Dario Vitali es profesor ordinario de Eclesiología en la Pontificia Universidad Gregoriana de Roma. 
declinaciones de la communio resultan tan divergentes que hacen temer que, tras la formal adhesión al modelo, cada uno de los sujetos eclesiales lo declina según criterios de conveniencia, cuando no de oportunismo. En otras palabras, la eclesiología de comunión se parece a un recipiente en el cual cada uno conserva celosamente su propia idea de Iglesia, desde la que valora los demás elementos, incluida la cuestión del ministerio y de los ministerios en la Iglesia.

Tampoco podría ser de otra manera. Existe, en efecto, un vínculo estrechísimo entre Iglesia y ministerio, que atraviesa toda la historia de la Iglesia. En dicha historia, por cierto, el modelo de ministerio ha determinado siempre el modelo de Iglesia, y no al revés. Este dato resulta evidente sobre todo en el segundo milenio, cuando se elaboró el modelo piramidal de Iglesia para defender el primado pontificio, el cual, tras un largo camino iniciado en la reforma gregoriana, fue confirmado en el Vaticano ${ }^{1}$. Aun con todas sus justificaciones, lo que ese modelo establecía, como la otra cara de la moneda, era precisamente la exclusión de los laicos de cualquier papel activo en la Iglesia mediante la imposición de la dicotomía entre Ecclesia docens e Ecclesia discens. Si hoy, en nombre de una supuesta inversión de la pirámide operada por el Vaticano II, se robusteciese también el modelo de ministerio, atribuyendo a los laicos lo que era propio del ministerio ordenado, se recaería inevitablemente en el mismo error. Muchas polémicas surgidas en el posconcilio repiten este esquema, oponiendo el papel de los laicos al de la jerarquía, con el único resultado de acrecentar el conflicto en la Iglesia.

Para no caer en tal automatismo, necesitamos aprender la lección del Concilio, en el que el tema de los laicos fue repensado a fondo dentro de un marco eclesiológico diferente. Por otro lado, en ese cuadro el tema de la ministerialidad y de los ministerios laicales es solo embrionario: en los textos conciliares el término «ministerio» se aplica preferentemente al ministerio ordenado. Por tanto, la lectura que ofrezco vuelve a recordar la costosa recuperación del papel activo de los laicos en la Iglesia, finalmente aceptado por la eclesiología conciliar. Hago notar, no obstante, que esta recuperación no llega al reconocimiento del derecho de los laicos a participar en la misión de la Iglesia, pero sí llega, más radicalmente, a configurar un modelo de Iglesia - pueblo de Dios, en cuyo marco se abre un espacio distinto en el que el tema puede ser discutido. Precisamente será en el contexto de la teología del pueblo de Dios donde intentaré aclarar el tema de la ministerialidad de los laicos en la Iglesia.

1. Concilio Vaticano I, Constitución dogmática Pastor aeternus en la Iglesia de Cristo (18.7.1870) COD, 811-816. 


\section{EL MODELO PIRAMIDAL}

El tema de los laicos constituye sin duda una novedad impulsada por el Vaticano II. Para darnos cuenta, basta con recordar brevemente qué lugar ocupaban los laicos en el modelo de la eclesiología piramidal. Se trata de un modelo que se basa en disposiciones y principios promulgados por la reforma gregoriana, la cual, a su vez, fue el punto de llegada de procesos que se desarrollaron durante el primer milenio cristiano. Aun dentro de los estrechos límites de un artículo, merece la pena recordar cómo se llegó a absolutizar el sacerdocio ministerial como única forma de ministerio útil y necesario en la Iglesia, con la desaparición no solo de la primigenia variedad y riqueza de carismas y ministerios, sino de toda función activa en la Iglesia de cuantos no formaban parte de la jerarquía.

Más allá de la fácil idealización de los orígenes de la Iglesia, que corre el riesgo de convertirse igualmente en una fácil simplificación, es necesario contemplar el rico y variado panorama de carismas y ministerios que los escritos del Nuevo Testamento testimonian. No obstante, ya el mismo Nuevo Testamento manifiesta cómo esa variedad de servicios y funciones pasa por un proceso de restricción y sobre todo de institucionalización, que concluye con la afirmación en la Iglesia de una estructura ministerial articulada en la tríada obispo-presbiterio-diáconos. En el epistolario paulino se pueden rastrear las etapas de un desarrollo que permite entrever los sujetos que componían en el siglo Il la jerarquía eclesiástica. Si 1 Cor 12, 4-31 documenta la floración de los carismas como manifestaciones del Espíritu en orden a la edificación del cuerpo (1 Cor 12,4), ya Ef 4, 7-16 muestra que tal riqueza de carismas tiende a ser reordenada según un criterio jerárquico. Se advierte el cambio de un horizonte pneumatológico a otro cristológico, que modifica el criterio de lectura de la realidad. Así, no se habla ya de carismas, sino de "gracia según la medida de Cristo» $(E f 4,7)$ y, por tanto, de funciones ligadas no a la acción del Espíritu Santo, que las distribuye como quiere (1 Cor $12,11)$, sino a personas que lo ejercen de modo estable: apóstoles, profetas, evangelistas, pastores y doctores. Aunque no se puede exagerar tal referencia, porque también 1 Cor 12, 28 abre la lista de carismas con apóstoles, profetas y maestros, es evidente el desplazamiento hacia un criterio ministerial, por cuanto resulta evidente que los apóstoles, profetas, evangelistas, pastores y doctores tienen la función de «capacitar a los hermanos para cumplir el ministerio con el propósito de edificar el cuerpo de Cristo» (Ef 4, 12).

En las cartas pastorales se advierte que las perspectivas se van cerrando (estrechamiento de horizontes). El clima de conflicto lleva al autor a insistir en la defensa de la verdad contra los falsos maestros. No es fácil reconstruir aquella situación, que quizás podría estar relacionada con el choque con los 
judaizantes, ampliamente documentado en los textos de Pablo; por ejemplo, según Tit 1, 10-14, esos maestros «que provienen de la circuncisión» turban a la comunidad «enseñando lo que no se puede enseñar». Tampoco es fácil trazar el perfil de esos "que enseñan», los cuales presentan los rasgos del didáscalo, pero también del profeta. Tales figuras, fundamentales en las cartas anteriores, sufren una drástica limitación de sus funciones en beneficio de los obispos, los presbíteros y los diáconos. Por esta razón, aunque no se puede afirmar que estas cartas reflejan la estructura jerárquica de la Iglesia, porque no dejan claras las relaciones entre las diversas figuras, es verdad que estas surgen como funciones importantes dentro de la comunidad cristiana en el momento decisivo del paso del tiempo apostólico al sub-apostólico, mostrando la progresiva institucionalización del carisma, con la consiguiente reducción del espacio a la libre iniciativa del Espíritu en favor de una estabilización de las figuras ministeriales.

Tal proceso se advierte también en la comprensión de la Iglesia: la imagen del cuerpo de Cristo como unidad de los miembros garantizada por el único Espíritu (1 Cor 12, 12-27) termina reemplazada por la del cuerpo como miembros unidos a Cristo-cabeza (Ef 1, 22-23; 4.7-16; Col 1, 18), para concluir, en los posteriores avances de la tradición paulina, con la Iglesia como «columna y fundamento de la verdad» (1 Tim 3, 15). Espíritu, Cristo, verdad remiten a tres principios diferentes para la vida de la Iglesia: el principio pneumatológico remite a la libertad de cada uno en la comunidad, que debe subordinarse, por supuesto, a la común edificación; el principio cristológico articula jerárquicamente las funciones según la mayor utilidad para el cuerpo de Cristo; el principio de la verdad distingue entre las funciones, llegando a eliminar algunas con el propósito de defender del error el cuerpo de Cristo. Aunque dicho tránsito se entendiera como una aplicación del criterio paulino de que «todo se haga para la edificación» (1 Cor 14, 26), traducido después en la imagen de la Iglesia como edificio construido «sobre el fundamento de los apóstoles y profetas y teniendo como piedra angular a Cristo» $(E f 2,20)$ y finalmente en la imagen de la Iglesia como «casa de Dios, columna y fundamento de la verdad» $(1 \operatorname{Tim} 3,15)$, el proceso de progresiva institucionalización de la Iglesia es evidente. El resultado es la estructuración jerárquica basada en la tríada obispo-presbíteros-diáconos, ya claramente testificada en las cartas de san Ignacio de Antioquía, a comienzos del siglo II. Cuanto más acaparan estas figuras las funciones ministeriales en la comunidad, tanto más las demás figuras tienden a desaparecer, cuando no a ser directamente eliminadas como peligrosas y desestabilizadoras.

A la «ministerialización» de los carismas y de la jerarquización de los ministerios, seguirá, en el siglo IV, la división del cuerpo eclesial en clero y lai- 
cos, como efecto del ingreso en la Iglesia de multitudes de paganos en respuesta al reconocimiento del cristianismo como religión del Imperio. Desde el edicto de Milán se asiste a una entrada en la Iglesia cada vez más masiva, motivada no por una conversión sincera, sino por oportunismo social. La mayoría de estas personas sólo está interesada en una pertenencia formal a la Iglesia, de modo que se demora de por vida en el catecumenado, sin llegar a asumir los exigentes compromisos de la vida cristiana. Este fenómeno establece la neta división de dos cuerpos en la Iglesia, con la consecuencia de comprometer a las fuerzas vivas de la comunidad en la formación y el cuidado de muchos catecúmenos, transformándolas en un grupo selecto, que tiende a identificase con los ministros, los cuales necesariamente van aumentando en número. En resumen, se encuentra aquí el origen de la diferenciación entre clérigos y laicos, que irá acentuándose cada vez más en un proceso de sacralización certificado por el cambio de vocabulario: la tríada obispo-presbíteros-diáconos tiende a ser sustituida por la más cultual de sumo sacerdote-sacerdote-levita, en una evidente recuperación del esquema veterotestamentario. La división neta de los espacios litúrgicos, con la reserva de un presbiterio al cual no tienen acceso los fieles, es solo la representación visible de una evolución que concluirá con la separación del cuerpo eclesial en dos bloques: clérigos y laicos.

Tal distinción no tendrá efectos lacerantes en el cuerpo eclesial hasta que la Iglesia se convierta en una Communio Ecclesiarum, articulada en diócesis, metrópolis y patriarcados. Este modelo eclesiológico, que identifica la Iglesia con un pueblo confiado al cuidado de un obispo, de su presbiterio y de sus diáconos, en el fondo es reconducible a un modelo de cuerpo cuyos miembros están unidos en la diferencia. Pero una lectura de este tipo deja de ser posible cuando del modelo de Communio Ecclesiarum se pasa al de Ecclesia universalis. Propiciado por una serie de circunstancias, tal modelo, introducido por la reforma gregoriana, concibe la Iglesia como una gran circunscripción eclesiástica bajo el gobierno del papa, y a los obispos como funcionarios que lo representan en los distintos distritos territoriales. En un escenario tan amplio, las diferencias tienden a incrementarse, a medida que la jerarquía se constituye en un círculo cerrado en torno al papa, mientras que los fieles tienden a transformarse en una masa indistinta -la universitas fidelium-a la que cada vez se le reconoce menos un papel activo. A las dos clases de cristianos se les asignan también fines diversos: la santidad queda reservada a los clérigos, mientras que los laicos se contentan con la salvación del alma².

2. Cf. Graciano, Concordia discordantium canonum, más conocido como Decretum Gratiani. «Duo sunt genera christianorum. Est autem genus unum, quod mancipatum divino officio, ac deditum contemplationi et orationi, ab omni strepitu temparalium cessari 
Cuando la Reforma protestante pone en tela de juicio la estructura jerárquica de la Iglesia, la respuesta católica reafirma la necesidad de la jerarquía, distinguiendo una potestas ordinis, relativa al cuerpo eucarístico, y una potestas iurisdictionis, relativa al cuerpo eclesial, que viene a reforzar la división entre clérigos y laicos. Resultado último de este proceso es la definición del primado de jurisdicción, sancionado por el Vaticano I, donde al dogma de la infalibilidad del papa le corresponde al revés la infalibilidad pasiva de los fieles. No por casualidad, la eclesiología posterior al Vaticano I concebirá la Iglesia en una relación asimétrica de autoridad y obediencia entre Ecclesia docens, depositaria de toda función activa en la Iglesia, y Ecclesia discens, en actitud subordinada de obediencia.

\section{EL RETORNO DE LOS LAICOS}

Paradójicamente, justo en el tiempo menos favorable es cuando se empieza a prestar atención a los laicos. Ya antes del Vaticano I había nacido en Bolonia, en 1867, la Sociedad de la juventud católica, que, en una forma de asociacionismo nueva, caracterizada por la presencia en la sociedad, reunía a católicos italianos para defender los derechos de la Santa Sede y los valores cristianos. La suspensión sine die del concilio y la decisión del papa de refugiarse en los palacios vaticanos después de la toma de Roma, en septiembre de 1870, determinan una ausencia de la Iglesia en la vida civil, ampliada por el non expedit, que negaba la participación de los católicos en las elecciones y, en general, en la vida política italiana. En el intento de acortar distancias, promoviendo una presencia cristiana en la sociedad que sirviese de elemento de contraste frente a la ideología laica, nació la Obra de los congresos, que desde 1874 hasta 1904, año de su supresión, reunió a los católicos italianos en una asociación articulada a nivel parroquial, diocesano y nacional, en defensa de los derechos religiosos.

En su lugar, en 1905 nace la Acción católica, por decisión de Pío X. El papa establece como objetivo específico el de «restaurar todo en Cristo: no sólo aquello que forma parte propiamente de la divina misión de la Iglesia de conducir las almas a Dios, sino también todo aquello que deriva espon-

convenit, ut sunt clerici, et Deo devoti. Videlicet conversi, kleros enim graece, latine sors. Inde huiusmodi hpmines vocantur clerici, id est sorte electi. Omnes enim Deus is suos elegit. Aliud vero est genus christianorum ut sunt laici. Laos enim est populus. Hic licet teporalia possidere, sed non nisi ad usum. Nighin enim miserius est quam postea nummum Deum contemnere. His concesus est usorem ducere. Terram colere, inter virium et virium iudicare, causas agere, oblationes super altaria ponere, decimas reddere et ita salvari poterunt. Si vitia bene faciendo evitaverint» (ibid., secunda pars, causa XII, q. I, c. VII, en Corpus luris caninici, Lipsiae 1879, 678). 
táneamente de esa misión divina, la civilización cristiana en todos y cada uno de los elementos que la componen $)^{3}$. A partir de esta distinción, el papa indica que tal tarea compete a «aquellos grupos elegidos de católicos que se proponen reunir todas las fuerzas vivas, a fin de combatir con todos los medios justos y legales la civilización anticristiana» ${ }^{4}$. Tras detallar las formas de presencia de los laicos en la sociedad, Pío X afirma:

El conjunto de esas obras sostenidas y propuestas en gran parte por el laicado católico, y de diversas formas ideadas en función de las necesidades de cada nación y de las circunstancias particulares en las que se encuentra cada país, es precisamente lo que, con términos particulares y puros, se suele llamar acción católica, o también acciones de los católicos. Esta en toda circunstancia viene en ayuda de la Iglesia, y la Iglesia ha escuchado y bendecido siempre tal ayuda, si bien según los tiempos se ha explicado de diversas formas ${ }^{5}$.

De este texto se colige con claridad la identificación de la Iglesia con la jerarquía, distinta netamente del laicado católico, considerado como una ayuda a los pastores de la Iglesia. Se trata de una lógica de colaboración, según la cual la jerarquía, a la que compete el fin primario de la salvación de las almas, permite a los laicos realizar, de forma subordinada, el fin secundario de defender los valores cristianos en la sociedad. Para subrayar las diferencias entre las acciones espirituales del clero y las acciones sociales del laicado, el papa acaba la encíclica reiterando la estrecha dependencia de la Acción católica de la jerarquía: de la autoridad eclesiástica deben depender, en efecto, no sólo «todas aquellas obras que directamente acudan en ayuda del ministerio pastoral de la Iglesia y que se propongan un fin religioso en beneficio directo de las almas», sino también «todas las otras obras que están destinadas a instituir y restablecer en Cristo la verdadera ciudad cristiana, y que constituyen en el sentido expuesto la acción católica» ${ }^{6}$.

Se abre así el vasto campo del apostolado de los laicos, motivado por la colaboración con la jerarquía: el modelo de dos cuerpos separados-Ecclesia docens y Ecclesia discens- se refleja en el esquema de colaboración en planos distintos, que asigna a los ministros sagrados el culto y a los laicos el vasto mundo. Así, la función propia del clero es la sacerdotal, mientras que la función de los laicos es la regia. En el fondo, este esquema se reproduce sin cesar en la teología anterior al Vaticano II, con el propósito de profundizar en el tema de la participación de los laicos en la misión de la

3. Pío X, Encíclica Il fermo propósito (11.6.1905), en Pío X acta II, 112-132. Enchiridion delle encicliche (EE) 4, 118-134, en especial 110.

4. EE 4, 114.

5. EE 4, 115.

6. EE 4, 118. 
Iglesia, pero también en la teología de las realidades terrestres ${ }^{7}$. Basta leer la famosa obra de Y. M. Congar Jalones para una teología del laicado ${ }^{8}$ para darse cuenta de ello: asumida la dualidad Iglesia-mundo, constituidos en dos órdenes diferentes, el teólogo dominico asigna a la jerarquía la función del «medio de gracia que nos une a la plenitud de la Pascua» ${ }^{9}$-por tanto, la función sacerdotal- y a los laicos la función -típicamente regia- de «reconducir a Dios, a través de Cristo, la historia y el mundo» ${ }^{10}$. Si acaso, la diferencia se reasume desde el principio que justifica el apostolado de los laicos: es mérito de la teología haber superado la idea de colaboración subordinada a la jerarquía, para fundamentarla en la misma condición cristiana, como derecho nato derivado del bautismo.

Será este el marco interpretativo adoptado en el esquema De Ecclesia presentado a los padres al final de la primera sesión del Vaticano II. El capítulo VI de dicho esquema ${ }^{11}$, completamente refundido más tarde en el «esquema Philips» que se presentó al comienzo de la segunda sesión, proponía una reflexión en ocho números, que enraizaba el apostolado de los laicos en el principio de que «en la Iglesia incumbe a todos los fieles la honrosa tarea de trabajar para que la voluntad divina de salvación sea siempre propuesta en todo tiempo y a todos los hombres $\rangle^{12}$. Sorprende que se base tal afirmación en la cita de Pastor aeternus del Vaticano I sobre la Iglesia, en la cual «todos los fieles se mantienen en unidad por el vínculo de una sola fe y una sola caridad» ${ }^{13}$. De esto se deduce que todos los miembros de la Iglesia, constituidos en unidad bajo un solo jefe, colaboran, cada uno según su condición específica, en el crecimiento del cuerpo. La participación en la misión de la Iglesia se fundamenta en el sacerdocio universal de los fieles ${ }^{14}$, que permite definir a los laicos no sólo como no-clérigos, sino, en positivo, como «los fieles insertos en el pueblo de Dios mediante el bautismo, cuya condición en el mundo está regulada únicamente por las normas de la vida cristiana ${ }^{15}$. La descripción basada en la diferencia respecto del estado clerical y el religioso, lleva a concretar la tarea del laico en «perseguir de un modo peculiar [o sea, según el propio estado] la santidad cristiana para

7. Sobre este tema, cf., por ejemplo, G. Thils, La Théologie des réalités terrestres I-II,

Paris 1946-1949; versión cast.: Teología de las realidades terrenas, Bilbao 1948.

8. Y. M. Congar, Jalons pour une Théologie du laicat, Paris 1954.

9. Ibid., 143.

10. Ibid., 151.

11. Cf. Acta Synodalia I/IV, 38.42 .

12. Esquema De Ecclesia, 20, en Acta Synodalia I/IV, 38.

13. Concilio Vaticano I, Pastor aeternus, Prólogo, en COD, 811.

14. De Ecclesia, 21, en Acta Synodalia I/IV, 38-39.

15. Ibid., 22, en Acta Synodalia I/IV, 39. 
la gloria de Dios con las obras, incluso las seculares ${ }^{16}$. $Y$ tales hechos no dependen de ninguna concesión de la jerarquía, sino que radica en la misma condición cristiana. Así, el n. 23 del esquema fundamenta los derechos y deberes de los fieles en los sacramentos de la iniciación cristiana, indicando que la participación de los laicos en la misión de la Iglesia consiste sobre todo en procurar la santidad de vida. Participación que el texto circunscribe en general a tres niveles: a) el apostolado de carácter específicamente religioso y, por eso, subordinado a la jerarquía; b) la promoción indirecta de la fe cristiana y de sus valores en el mundo: c) la consecratio mundi, o sea, la acción que permite que el Espíritu de Cristo penetre en todas las actividades humanas. Sobre esta base se especifican las principales formas de colaboración de los laicos a la misión de la Iglesia: individual y asociativa; directa en la esfera propiamente religiosa o en la profana, la cual atañe sobre todo a los laicos, en nombre de «una sana autonomía de la ciudad secular».

El texto que los padres tendrán en sus manos al comienzo de la segunda sesión, debidamente revisado por la Comisión doctrinal, mantendrá de manera sustancial el conjunto del primer esquema, tan solo ampliando la parte introductoria ${ }^{17}$. En lugar de la cita del Vaticano I, se señala que, tras haber aclarado las funciones de la jerarquía en la Iglesia, la intención del concilio será ahora ilustrar «la condición y la misión de los laicos», afirmando que «este pueblo, constituido en comunidad de caridad y verdad, es, unido a Cristo, instrumento de redención y, como tal, enviado al mundo entero» ${ }^{18}$. La definición de laico se enriquece en el n. 23 del esquema, que presenta lo que asemeja y diferencia a los miembros de la Iglesia ${ }^{19}$. El punto de partida es la idea de pueblo de Dios, en el cual se da la igualdad de todos sus miembros, que participan de la misma dignidad por la regeneración en Cristo de la misma gracia de ser hijo de Dios, de la misma llamada a la santidad, de la misma salvación, de la misma esperanza y caridad, de los mismos medios de salvación, de los cuales somos todos destinatarios. Por tanto, «ninguna desigualdad en Cristo», sentencia el esquema, por cuanto «a todos se les concede aquel sacerdocio real mediante el cual Cristo nos ha constituido en reino y en sacerdotes para su Padre $(A p 1,6) »^{20}$. «Aunque no todos en la Iglesia avanzan por el mismo sendero [...], sin embargo todos son llamados

16. Ibid.

17. Cf. Schema compensiosun de Ecclesia, caput III: De populo Dei et speciatim de laicis, en Acta Synodalia II/I, 256-268.

18. Ibid., 22, en Acta Synodalia, 256.

19. De membrorum in Ecclesia Christi aequalitate et inaequalitate, en Acta Synodalia II/I, 257-258.

20. Ibid., 257. 
a la misma santidad». La ulterior distinción del cuerpo eclesial en jerarquía y pueblo Dios, pastores y fieles, se dirige a que unos y otros, según su propio estado, colaboren a la obra de la salvación. Por eso conserva gran valor la descripción de los laicos como «fieles que, insertos por el bautismo en el pueblo de Dios, sirven a Dios en el común estado de fieles cristianos $y$, en cuanto es propio (et pro parte sua), ejercen en el mundo la misión de todo el pueblo cristiano, también a través de una acción religiosa, pero sin pertenecer directamente a los estados clerical o religioso, aprobados por la Iglesia» ${ }^{21}$.

\section{LAICOS O Pueblo de Dios}

El largo camino de recuperación de los laicos parece finalmente abierto en el esquema De Ecclesia. Aunque con múltiples matizaciones, signo de una cierta dificultad para aceptar la participación de los laicos en la vida y la misión de la Iglesia, el proceso parece felizmente concluido. A partir del fundamento de la igual dignidad de todos los miembros de la Iglesia, se acepta por fin el derecho de los laicos al apostolado y se reconoce su acción en el mundo como participación en la función real de Cristo. En este contexto, se podría elaborar una teología de los ministerios laicales muy aceptable. No obstante, el largo y complejo camino de recuperación de los laicos entre los dos concilios vaticanos no termina con el Schema compendiosum y las afirmaciones sobre la participación de los laicos en la misión de la Iglesia. Durante las discusiones en el aula sobre el capítulo $D e$ populo Dei et speciatim de laicis, el cardenal Suenens propone redactar un nuevo capítulo De populo Dei, distinto del que se había redactado sobre los laicos, que debe incluirse inmediatamente después del capítulo I, sobre el misterio de la Iglesia, antes del de la constitución jerárquica de la Igle$\mathrm{sia}^{22}$. La propuesta respondía al hecho de que los primeros párrafos no se referían propiamente a los laicos, sino a todos los bautizados, cualquiera que fuese su estado de vida, y situaba a todos los miembros de la Iglesia en una condición de radical igualdad en virtud de la regeneración en Cristo. El nuevo capítulo fue redactado a partir del párrafo sobre el sacerdocio universal de los fieles, como tema en torno al cual estructurar fundamentalmente la teología del pueblo de Dios. Esta simple inversión en el orden del tratado -el pueblo de Dios antes que la jerarquía- propició la «revolución copernicana en eclesiología, que no solo da la vuelta -si a esto se limitase,

21. Ibid., 258.

22. Cf. Acta Synodalia II/I, 324-329. 
la pirámide seguiría siendo una pirámide-, sino que además desarticulada esta estructura a partir de la idea de la radical condición de igualdad de todos los miembros de la Iglesia, más allá de cualquier diferencia vocacional, de función y de estado de vida».

Para comprender la aportación de esta revolución, es necesario fijarse en la relación entre el sacerdocio ministerial y el sacerdocio universal de los fieles, que el texto recibido califica como «común» para subrayar la común condición de todos los bautizados, capacitados para ofrecer a Dios sacrificios agradables a él. La descripción de esta forma de participación del pueblo santo de Dios en el sacerdocio de Cristo no cambia respecto al texto primero, y sin embargo la inversión de los sujetos cuestiona una relación asimétrica consolidada a lo largo de los siglos: si en el primer esquema $D e$ Ecclesia la superioridad del sacerdocio ministerial o jerárquico respecto al sacerdocio regio era tal que se podía calificar «tanto de grado como de esencia» ${ }^{23}$, la precedencia del sacerdocio común sobre el jerárquico, dictada por el nuevo orden de los capítulos, no solo cancela la lógica de la subordinación, sino además que determina una nueva comprensión del sacerdocio ministerial como función esencialmente referida al sacerdocio común, desde la perspectiva del servicio al pueblo de $\operatorname{Dios}^{24}$. Sin cambiar nada de cuanto es propio de la constitución jerárquica de la Iglesia, desaparecen -al menos en principio- siglos de «jerarcología», construida sobre la relación asimétrica entre Ecclesia docens y Ecclesia discens. En virtud de esta simple modificación redaccional, cambia radicalmente la lógica que se limitaba a subrayar la dimensión sacerdotal y real de la vida cristiana, identificando la primera con la ofrenda de sacrificios espirituales, y la segunda con la presencia y acción en el mundo para promover los valores cristianos y edificar el reino de Dios. Aquel esquema binario, en el fondo, reduplicaba y llevaba a consecuencias extremas la distinción entre potestas ordinis et iurisdictionis: como se ha visto en el mandato de Pío X a la Acción católica, al clero le compete el culto y a los laicos la acción en el mundo, la función propiamente real de consagración de la realidad terrestre. El replanteamiento de la función jerárquica según el esquema de los tria munera -docendi, santificandi, regendi ${ }^{25}$ - encuentra su correspondencia en la triple participación de los

23. Este era el sentido de la fórmula de Pío XII recuperada en el primer esquema $D e$ Ecclesia y reintroducida en el Schema receptus; cf. Acta Synodalia III/I, 183-184.

24. Sobre este punto, cf. mi artículo Sacerdozio commune e sacerdozio ministeriale o gierarchico: rilettura di una questione controversa: Rassegna di Teologia 52 (2011) 39-60.

25. Cf. LG 25-27 para los obispos, aplicado en LG 28 a los presbíteros (Enchiridion Vaticanum [EV] 1/354ss). El esquema se repite después en diversos decretos: cf. en particular Chistus Dominus (CD) 12-16, en EV 1/596ss; Presbiterorum ordinis (PO) 4-6, en EV $1 / 250$ ss. 
laicos en la función profética, sacerdotal y real de $\mathrm{Cristo}^{26}$, dando testimonio ante todo con una vida fiel y de caridad, y ofreciendo a Dios un sacrificio de alabanza fruto de los labios que celebran su nombre (Heb 13, 15).

Como formas de participación del pueblo de Dios en la función profética de Cristo, LG 12 propone el sensus fidei y los carismas, tras haber aclarado en la primera parte del parágrafo que «la totalidad de los fieles que han recibido la unción del Santo (1 Jn 2, 20.27) no puede equivocarse en el creer, y manifiesta esta propiedad peculiar mediante el sentido sobrenatural de la fe de todo el pueblo, cuando, 'desde los obispos hasta los últimos fieles laicos', manifiesta su consenso en materia de fe y de moral». El texto introduce el tema de los carismas como aspecto ulterior de la presencia y acción santificadora del Espíritu.

El mismo Espíritu Santo, además, santifica al Pueblo de Dios, y lo conduce adornándolo de virtudes, no solo por medio de los sacramentos y los ministerios, sino también "dispensando a cada uno como quiere» sus dones (1 Cor 12, 11), distribuyendo entre los fieles de cada estado gracias especiales que los capacitan y preparan para asumir funciones y acciones útiles para la renovación y el mayor progreso de la Iglesia, según las palabras: "A cada uno se le manifiesta el Espíritu Santo para utilidad común» (1 Cor 12, 7).

Después del párrafo sobre el sensus fidei, el texto menciona una secuencia muy articulada de acciones del Espíritu en una combinación paratáctica de sacramentos, ministerios, virtudes y carismas, para introducir «los carismas como dones que, con vistas al incremento del apostolado en la Iglesia, el Espíritu distribuye como quiere entre los fieles en razón del servicio o 'diaconía'» ${ }^{27}$. Precisaba el esquema que se trata de dones no siempre ni solamente extraordinarios, sino también sencillos y ampliamente difundidos, apropiados y beneficiosos para la renovación de la Iglesia. En lugar de prop-

26. Cf. LGF 34-37. El esquema no parece aplicado al pueblo de Dios, porque no existe una sesión en la que se dediquen por separado tres apartados a la función sacerdotal, profética y real. En realidad, LG 11, hablando del sacerdocio común a través de los sacramentos y las virtudes, se refiere a las funciones sacerdotales y reales, y LG 12 rara vez a la función profética.

27. Textus prior in acta Synodalia III/I, 185-186. El texto no hacía otra cosa que retomar el capítulo IV de la adhumbratio schematis constitutionis de Ecclesia, propuesta por obispos alemanes y austriacos, que en el n. 40, dedicado a los dones, precisa: «En ocasiones, para un mayor y más eficaz crecimiento de la Iglesia y del apostolado, el Espíritu Santo confiere a los laicos, como también a los demás miembros de la Iglesia, dones carismáticos extraordinarios. Se trata de medios adaptados a las peculiares necesidades de la Iglesia, a los cuales, sin embargo, no hay que conformarse temerariamente ni esperar de ellos presuntuosamente el fruto de las obras apostólicas; se deben ante todo recibir con humildad y consuelo de Dios que los concede y subordinarlos al juicio y la disciplina de la Iglesia» (De Ecclesia, 40, en Acta Synodalia I/IV, 630). 
terea, el texto definitivo dice praeterea, subrayando así la diferencia con los otros dones del Espíritu. Se puede vislumbrar aquí la distinción tradicional entre gratia gratum faciens y gratia gratis data. La decisión de distinguir los sacramentos y los ministerios fue de la comisión doctrinal, con el fin de evitar inútiles equívocos. La comisión precisó mejor la finalidad de los carismas, que no es tanto el incremento del apostolado en la Iglesia «cuanto la renovación en la Iglesia y su mayor desarrollo» ${ }^{28}$.

Precisamente el tema de los carismas ofrece un espacio inédito de libertad para la presencia y la acción de los bautizados en la Iglesia, sin otro fundamento que la gracia del Espíritu Santo, el cual distribuye sus dones a quien quiere y como quiere. Lo que está en juego se percibe en el debate que entablaron en el aula los cardenales Ruffini y Suenens. Para Ruffini, los carismas, demasiado enfatizados en el texto, son dones extraordinarios que se circunscriben a los comienzos de la Iglesia, no dones concedidos todavía hoy, y en cualquier caso no concedidos con profusión, como demuestra la experiencia ${ }^{29}$. Para Suenens, los carismas, lejos de ser «un fenómeno periférico y no sustancial en la vida de la Iglesia», tienen "una importancia vital para la edificación del cuerpo místico»: consisten, en efecto, en dones extraordinarios, pero también sencillos y ordinarios, que el Espíritu no solo distribuyó en los orígenes, sino que otorga también hoy entre todos los miembros de la Iglesia, sea cual sea el estado y grado al que pertenezcan ${ }^{30}$.

La comisión doctrinal aceptó la perspectiva del cardenal Suenens, explicando que «carisma es, en Pablo, una denominación de múltiples significados, que incluye también, o al menos específicamente, ministerios estables», y cita como referencias Rom 12, 6-13; 1 Cor 12.7-11.28-31; 14, 2ss; 16, 15-16; Ef 4, 11-12. Y añadía que «la palabra debe entenderse como referida a una variedad de dones, que por todas partes (passim) son concedidas por el Espíritu Santo con cierta regularidad tanto a los ministros como a los fieles», especificando además que «los carismas no siempre manifiestan un carácter extraordinario y visible, como los milagros, las lenguas, las apariciones, etc., pero el don se manifiesta en la caridad y en cualquier don particular que redunda en beneficio de la comunidad ${ }^{31}$.

28. Relatio de n.12, en Acta Synodalia I/IV, 630.

29. Acta Synodalia II/II, 627; cf. apéndice 3, n. 2. En conclusión, sobre su intervención el cardenal de Palermo observa: «Para el apostolado y para el incremento de la Iglesia no podemos recurrir a los laicos carismáticos, desde el momento en que los carismas -al contrario de lo que piensan muchos hermanos separados, los cuales hablan alegremente del servicio de los carismáticos en la Iglesia- son hoy muy raros y del todo excepcionales (singularia)».

30. Para la intervención de Suenens, cf. Acta Synodalia II/III, 175-178.

31. Cf. ibid., II//, 266; Apéndice 3, n. 2. 


\section{4. ¿APOStOlAdO DE LOS LAicos SÍ, MINISTERIOS LAICALES NO?}

No se puede decir que el horizonte abierto con la recuperación de los carismas haya penetrado en la conciencia y la vida de la Iglesia. La articulada propuesta del cardenal Suenens (1. abordar en el capítulo sobre el pueblo de Dios, junto a la estructura ministerial, también la dimensión carismática de la Iglesia; 2 . tratar más amplia y concretamente la dimensión carismática del pueblo de Dios, 3. en particular, lo referido a los profetas y doctores; 4 . describir en términos positivos y constructivos las disposiciones de los pastores respecto de los carismas de los fieles, 5. sin olvidar la doctrina paulina sobre la libertad de los hijos de Dios en la Iglesia) ${ }^{32}$ ha conocido una recepción débil e inconstante. A esta deriva puede haber contribuido el encendido debate sobre carisma e institución en el inmediato posconcilio, así como la insistente referencia a los carismas por parte de la Renovación carismática, prestando más atención al aspecto extraordinario de los carismas que al ordinario. De hecho, no parece esta la vía que suela invocarse para reconocer al pueblo de Dios con una efectiva capacidad de presencia y de acción en la Iglesia y en el mundo. Paradójicamente, mientras que, por un lado, el término ha experimentado un proceso de hinchamiento, deviniendo omnicomprensivo de toda realidad eclesial, por otro está perdiendo fuerza poco a poco, quedando reservado para la persona carismática o el fenómeno extraordinario y milagroso.

No parece haber corrido mejor suerte el tema de los ministerios laicales. Un feliz comienzo parecía el motu proprio Ministeria quaedam de Pablo $\mathrm{VI}^{33}$, que cancelaba las órdenes menores y transformaba el lectorado y el acolitado en ministerios instituidos, de modo que quedase más claro lo que era competencia de los ministros y lo que puede ser confiado a los laicos ${ }^{34}$. La disposición remitía a Sacrosanctum Concilium (SC) 28, según la cual «cada uno, ministro o fiel, desempeñando su profesión, cumple solo y todo lo que le compete según la naturaleza del rito y las normas litúrgicas». De este modo, el ejercicio ordenado del ministerio en la asamblea litúrgica manifiesta "la Iglesia conformada en sus varios órdenes y ministerios»" ${ }^{35}$. El motu proprio abre un vasto horizonte a la ministerialidad en la Iglesia:

Además de los ministerios comunes a toda la Iglesia Latina, nada impide que las Conferencias Episcopales pidan a la Sede Apostólica la institución de otros que, por razones particulares, crean necesarios o muy útiles en la propia re-

32. Cf. ibid., II/III,177.

33. Pablo VI, motu proprio Ministeria quaedam (15.8.1972), en EV 4, 1749-1770.

34. Ibid., EV 4, 1754.

35. Ibid., EV 4, 1752. 
gión. Entre estos están, por ejemplo, el oficio de Ostiario, de Exorcista y de Catequista, y otros que se confíen a quienes se ocupan de las obras de caridad, cuando esta función no esté encomendada a los diáconos ${ }^{36}$.

Después del párrafo sobre los ministerios instituidos, se ha hablado con gozo de Iglesia ministerial, planteando la hipótesis de la institución de nuevos ministerios: del catequista, del cantor-salmista, del sacristán, de ministerios orientados a la organización caritativa ${ }^{37}$. Pero la decisión de tomarse un tiempo para «sopesar en la práctica las instituciones del acolitado y el lectorado» ha llevado a la pérdida de interés por el tema, impulsando a encuadrar la vasta tipología de los servicios y funciones asumidos por los laicos bajo el nombre de "ministerios de hecho», de manera que los únicos ministerios reconocidos a los laicos se encuentran relacionados con el ámbito litúrgico. En última instancia, este ha sido el marco prevalente en el que se ha situado la invitación a participar, incluso en forma de reivindicación de los laicos y de concesión por la jerarquía, en la vida y en la misión de la Iglesia.

¿Por qué este resultado? Porque la afirmación de que la Iglesia, «por institución divina organizada y regida con admirable variedad» (LG 32), en razón del único cuerpo de Cristo, en el que los diferentes miembros no tienen la misma misión, no se ha traducido en el reconocimiento de una ministerialidad extendida a todos los miembros del cuerpo, «cada uno según su propia condición». De aquella afirmación del principio, LG 32 deducía que «entre todos los miembros de la Iglesia se da verdadera igualdad en cuanto a la dignidad y a la acción en la tarea de edificar el cuerpo de Cristo»: "La diversidad de la gracia, de los ministerios y de las operaciones sirve para congregar en unidad a los hijos de Dios, porque 'es el mismo Espíritu Santo el que obra en todas estas cosas' (1 Cor 12, 11)». A continuación el concilio introducía el tema del apostolado de los laicos como «participación en la misión salvífica de la Iglesia», afirmando que «todos los laicos, sin distinción, están llamados a contribuir como miembros vivos al incremento de la Iglesia y a su santificación» (LG 32), antes que nada con el testimonio de vida cristiana en aquellos lugares donde la Iglesia más difícilmente puede hacerse presente, pero también con una posible llamada directa, «en orden a una colaboración más inmediata con el apostolado de la jerarquía» (LG 33). A

36. Ibid., EV 4, 1755.

37. Con el documento pastoral del episcopado italiano Los ministerios en la Iglesia (15.8.1972), que imaginaba como «el área del libro del altar, de la Iglesia, se hará más compartido y más coparticipada por los presbíteros y los laicos, contribuyendo al crecimiento de la comunidad viva y educada a leer los ministerios no como hechos privados o títulos honoríficos» (ibid., en Enchiridion CEI 2, 596.598). 
partir de tales supuestos, el concilio explicaba la participación de los laicos en la función sacerdotal, profética y real de Cristo (LG 34-36).

Aunque el concilio emplea incluso prevalentemente el término «ministerial» para el ministerio ordenado - llamado de forma diferente «jerárquico», «eclesiástico», «sacerdotal»-, se cierne sobre el cuadro eclesiológico del Vaticano II el principio de la ministerialidad como constitutiva de la estructura y la vida de la Iglesia. Lo demuestra el íncipit del capítulo III sobre la constitución jerárquica de la Iglesia, que, con vistas a armonizar con el capítulo II, afirma: «Para alimentar y aumentar cada vez más el Pueblo de Dios, Cristo el Señor ha instituido en su Iglesia diversos ministerios» (LG 18) cuya actividad -en particular, la de los «ministros dotados de potestad sagrada»- debe regirse por la lógica del servicio. El principio, sin embargo, no encuentra fácil aplicación al apostolado de los laicos, dado que el concilio no define con claridad el ámbito y la naturaleza de tal apostolado: ¿se trata de una presencia en el mundo o de una acción en la Iglesia, directamente asociada a la de la jerarquía? Muy diferente será la forma de los ministerios laicales según estos correspondan al carácter propiamente secular de los laicos, a los que corresponde «buscar el reino de Dios ocupándose de las realidades temporales y ordenándolas según Dios» (LG 31), o consistan en una acción intraeclesial, en forma de colaboración directa con la jerarquía. A diferentes ambientes, diversas modalidades y condiciones de ejercicio. En última instancia, el concilio no ha resuelto la dicotomía, por lo cual el discurso sobre el ministerio de los laicos padece de esta indeterminación.

Por otra parte, las dos formas de apostolado nos llevan a dos sujetos distintos o, al menos, a dos fisonomías distintas de laico. En relación a la posibilidad de «hacer presente y operante a la Iglesia» en el mundo, al ser fieles laicos está claro que se trata de bautizados, llamados a ser testigos de Cristo según la propia condición, que se denomina laical para distinguirla de la clerical y la religiosa, las cuales tienen una finalidad y unos ámbitos de actuación distintos. En tal dirección apunta la precisión de que «este apostolado se refiere a todos los fieles cristianos» (LG 33). Se trata, en última instancia, de una reduplicación de cuanto ya se ha dicho en el capítulo II de Lumen gentium sobre el pueblo de Dios. Además, el perfil de los laicos diseñado sobre la base de la diferencia con el estado clerical y religioso orientaría a la configuración de un estado laical paralelo. Pero el concilio no se explaya en esta dirección, limitándose a afirmar el carácter secular de tal apostolado.

La otra forma de apostolado es descrita como una llamada a «una colaboración más inmediata con el apostolado de la jerarquía» (LG 33), contemplando incluso la posibilidad de «ser asumidos por la jerarquía para ejercer algunas funciones eclesiales, para un fin espiritual» (ibid.), sin explicitar cuá- 
les. De hecho, en los parágrafos que describen la participación de los laicos en la función sacerdotal, profética y real de Cristo (LG 34-36), nunca aparece ninguna tematización de los ministerios de los laicos. En la referencia a la función sacerdotal, LG 34 no cita ministerios litúrgicos e identifica la función sacerdotal de los laicos con el mismo acto de ofrenda de los sacrificios espirituales, «porque tenemos que ejercitarnos en el culto espiritual para gloria de Dios y la salvación de los hombres»: ni más ni menos que cuanto dice LG 10 sobre el sacerdocio común. De hecho, la participación en la liturgia prepara a los bautizados a producir frutos cada vez más abundantes. Todas sus obras, oraciones e iniciativas apostólicas, la misma vida conyugal y familiar, el trabajo diario, la recreación espiritual y corporal, si se hacen en el Espíritu, y también el mismo sufrimiento de la vida, si es soportado con paciencia, se convierten en sacrificios espirituales agradables a Dios por Jesucristo $(1 \mathrm{Pe}$ 2, 5). En el fondo, el texto parece desplazar el acento desde los ministerios a la vida, desde la competencia al testimonio. El discurso no cambia cuando se abordan las funciones profética y real: la insistencia se centra en el testimonio de la vida cristiana, a nivel personal, familiar, social, sin indicar formas de ministerio específico de los laicos en estos ámbitos.

En otras palabras, la facilidad con que el concilio habla del apostolado de los laicos no se traduce en una pareja facilidad para configurar los ministerios de los laicos. Cuando se entra en este terreno, el lenguaje se vuelve cauto, impreciso, con una llamada explícita al tema de la colaboración, que en último término parece remitir a la consolidada relación asimétrica de autoridad y subordinación, y a su lógica de la concesión por parte de la jerarquía de espacios reducidos y, por lo general, secundarios respecto a un papel preponderante de los ministros ordenados.

Bajo esta ambigüedad ha surgido la demanda de una participación en la misión de la Iglesia, fundada en el bautismo, que no se reduzca a un genérico apostolado de los laicos o a la atribución de funciones delegadas, sino a un verdadero y propio reconocimiento del ministerio de los laicos. En este punto se ha registrado, sin embargo, una mayor cautela por parte de la jerarquía: al énfasis sobre la participación de los laicos en la misión de la Iglesia no ha correspondido un énfasis igual a la hora de definir esos «diversos ministerios» (LG 18) no reducibles al único ministerio jerárquico; al contrario, se ha puesto mucho cuidado en marcar escrupulosamente los límites de su competencia en el caso de suplencias en funciones propias del ministerio ordenado ${ }^{38}$.

38. El caso más emblemático es la instrucción interdicasterial Ecclesiae de mysterio (15.8.1997), con la firma de ocho organismos vaticanos, que fija los límites de la colaboración de los laicos en el ministerio de los sacerdotes, revocando muchas formas de ejercicio de la ministerialidad laical. 


\section{CONCLUSIONES}

Contra esta lectura se podía invocar la exhortación postsinodal Christifideles laici $(\mathrm{ChL})^{39}$, que puede ser definida como una verdadera y precisa enseñanza sobre la participación de los laicos en la vida y misión de la Iglesia. Este texto ha abierto, al decir de muchos, un periodo feliz para la teología del laicado, que podía hacer pensar en un éxito completo -entre otras cosas porque está sancionado por el magisterio del papa- del largo proceso de recuperación de los laicos iniciado en el siglo XIX, pasando por el concilio Vaticano II y llevado a plena madurez con el sínodo sobre los laicos. El texto afirma que la tarea de trabajar en la viña del Señor «no afecta solamente a los pastores, sacerdotes, los religiosos y religiosas, sino que se extiende a todos; también los laicos son personalmente llamados por el Señor, del cual reciben una misión para la Iglesia y para el mundo» (ChL 2). El rejuvenecimiento de la Iglesia en el posconcilio se hace depender de las «nuevas energías de santidad y de participación en tantos fieles laicos» que el Espíritu Santo ha suscitado:

Esto queda testificado, entre otros elementos, por el nuevo estilo de colaboración entre sacerdotes, religiosos y laicos, por la participación activa en la liturgia, por el anuncio de la palabra de Dios y la catequesis; por los múltiples servicios y tareas confiados a los fieles laicos y asumidos por ellos; por el gozoso refluir de grupos, asociaciones y movimientos de espiritualidad y compromiso laical; por la participación mayor y más significativa de las mujeres en la vida de la Iglesia y en el desarrollo de la sociedad (ibid.).

Pero, a pesar de que el texto hace coincidir el rejuvenecimiento de la Iglesia con el impulso de nuevas energías de santidad y participación de los laicos, no es difícil leer entre líneas la relación asimétrica pastores-fieles, expresada en el esquema de la colaboración. Por otra parte, a continuación el texto estigmatiza como una tentación el «mostrar un interés muy marcado por los servicios y las tareas eclesiales, de tal modo que frecuentemente se ha llegado a una práctica dejación de sus responsabilidades específicas en el mundo profesional, social, económico, cultural y político» (ibid.).

El hecho resulta mucho más sorprendente si tenemos en cuenta la insistencia con que se subraya el derecho-deber de los laicos a participar en la misión de la Iglesia. En otras palabras, se percibe una actitud ambivalente en la jerarquía: por una parte, el énfasis en el apostolado de los laicos, la im-

39. Juan Pablo II, exhortación postsinodal Christifideles laici, sobre la vocación y misión de los laicos en la Iglesia y en el mundo (30.12.1998), en AAS 81 (1989) 393-521; EV 11, 1606-1900. 
portancia de su tarea en la Iglesia; por otro, una especie de malestar cuando esta tarea se vuelve activa y, por esto, entra en espacios antes reservados exclusivamente a los ministros ordenados. Esto no puede deberse solo a una actitud de defensa de posiciones antiguas: se explica mejor por la debilidad del marco teológico en el que se encuentra la cuestión de los ministerios laicales. Más allá de las declaraciones de principios, aún no se ha superado la idea de la participación subordinada en la misión de la jerarquía, por mucho que se diga que los laicos participan en la misión de la Iglesia en razón del derecho que les confiere el bautismo. Cuando se trata de traducir dicha participación en funciones y ministerios, es siempre y únicamente la jerarquía quien decide si, cuándo y cómo se pueden ejercer, y siempre cuidando que el término «ministerio» aplicado a los laicos «no se perciba y viva como una indebida aspiración al ministerio, o como una progresiva erosión de su especificidad $\aleph^{40}$. Por supuesto, la prudencia se refiere a la misión de discernimiento propia de la jerarquía, pero también a un modelo aún muy clerical de Iglesia, donde la preocupación por defender y garantizar la especificidad del sacerdocio ministerial supera con mucho al deseo de promover las formas de ministerio laical que lleven al ejercicio del sacerdocio común.

Por otra parte, es la relación misma entre clérigos y laicos lo que alimenta la lógica de la competición entre ellos. Y esto no solo por los siglos de concentración de todas las funciones ministeriales en manos del clero. A menos que se cuestione la legitimidad del sacerdocio ministerial, cuando se trata de ministerios laicales, aunque motivados por el derecho innato a participar en la misión de la Iglesia en virtud del bautismo y no por delegación de la jerarquía, la lógica que regula este ejercicio es -inevitablemente- la de la concesión por parte de la jerarquía; en última instancia, la de la aprobación. Más allá de las afirmaciones de principio, existe la posibilidad real -hoy cada vez más frecuente, por desgracia- de que un ministro ordenado acapare funciones dentro de una comunidad, sin que eso sea percibido como un abuso. Esto demuestra que el modelo de la colaboración utilizado para justificar los ministerios de los laicos responde a una concesión, aceptada de mala gana, motivada por la actual escasez de sacerdotes, pero siempre revocable cuando se invierta la tendencia.

A mi juicio, este no es el camino para fundamentar y salvaguardar la ministerialidad de los laicos en la Iglesia y, más radicalmente, la ministerialidad de la Iglesia que no se reduzca al ministerio ordenado. Más adecuado es

40. Ecclesiae de mysterio, disposición práctica, art. 1, en EV 16, 669. Por eso la instrucción selecciona con cuidado el vocabulario, reservando munus et officium al ministerio ordinario y aplicado el adjetivo "extraordinario» a todas las otras formas de suplencia de los laicos en las funciones propias de los ministros ordinarios. 
reconducir el ministerio de los laicos hacia el sacerdocio común (cf. LG 10). Dada la diferencia de esencia y no tanto de grado en relación al sacerdocio ministerial, se garantiza la especificidad del ministerio ordenado, pero al mismo tiempo se ofrece un amplio espacio en el cual se puede legítimamente ejercer el sacerdocio común como participación en la función sacerdotal, real y profética de Cristo.

Se puede objetar que se trata de un espacio genérico. Sin embargo, se trata de un espacio real y amplio como el vasto mundo. La función del pueblo santo de Dios, en efecto, se traduce en la ofrenda de sacrificios espirituales, que consiste en presentar a Dios todo, «las alegrías y las esperanzas, las tristezas y las angustias de los hombres de hoy, sobre todo de los pobres» (GS 1). En lugar de pelearse por los espacios reducidos del presbiterio para ejercer únicamente funciones por delegación, los bautizados son llamados, sobre todo, a una presencia en el mundo, que puede ser traducida en forma de ministerialidad, personal y colectiva, que edifica el reino de Dios. ¿Cuál? «Tuve hambre y me disteis de comer, tuve sed y me disteis de beber, fui extranjero y me acogisteis, estuve enfermo y me visitasteis, estuve en la cárcel y vinisteis a verme» (Mt 25, 35-36).

Por otra parte, LG 12 pone el tema de los carismas en relación con el sacerdocio común, como participación en la función profética de Cristo. La Iglesia de los orígenes testifica claramente como los numerosos ministerios son formas de estabilización de los carismas que el Espíritu Santo había distribuido generosamente en la comunidad (1 Cor 12, 4-11.28-31; Ef 4, 11-16). ¿Qué impide que hoy la individualización de los ministerios necesarios y útiles para la Iglesia se haga a partir del discernimiento de los carismas que el Espíritu suscita continuamente en el cuerpo de la Iglesia? Obviamente, tal asunto comporta no solo creer que el Espíritu está actuando también hoy, sino aceptar que el discernimiento de la jerarquía no consista tanto en determinar los ministerios en la Iglesia, cuanto en reconocer cuáles son los carismas efectivamente suscitados por el Espíritu. En otras palabras, se trata de «no apagar el Espíritu, no despreciar las profecías, examinar cada cosa y retener lo bueno» (1 Tes 5, 19-21).

A mi parecer, el tema de los ministerios en la Iglesia es un capítulo que está por escribir -y por reescribir-. La teología debería hacerlo a partir de los carismas, y no del ministerio ordenado. De esta manera, el perfil no se vería condicionado por cuanto ya se ha dicho sobre el sacerdocio ministerial, sino por la libre iniciativa del Espíritu, que distribuye como quiere sus dones para la renovación de la Iglesia y para la salvación de los hombres. Así, los ministerios de la Iglesia serían reconducidos por dos principios -sacerdocio ministerial y sacerdocio común- que no son rivales, sino que están ordenados el 
uno al otro, porque ambos, peculiari modo, participan del único sacerdocio de Cristo (LG 10). Pero debería escribirlo cada Iglesia particular: en este momento eclesial concreto, dentro de las diversas situaciones de la historia y de la vida, en una apertura incondicional al Espíritu «que guía la Iglesia hacia la verdad completa, la unifica en la comunión y en el servicio, la edifica y la guía con diversos dones jerárquicos y carismáticos, y la enriquece con sus frutos» (LG 4). Esto porque, «en la edificación del cuerpo de Cristo, existe una variedad de miembros y de funciones... Uno solo es el Espíritu que distribuye sus dones para utilidad de la Iglesia, según sus riquezas y la finalidad de ministerios» (LG 7).

Exactamente, «según la diversidad de ministerios». El Señor que gobierna su Iglesia en un solo cuerpo mediante el Espíritu «sigue dispensando los dones de los ministerios [dona ministrationum] con los cuales, por su poder, estamos al servicio unos de otros, para que, viviendo según la verdad en la caridad, busquemos crecer en todo hacia él, que es nuestra Cabeza (cf. Ef 4, 11-16)» (LG 7). En vez de reivindicar un ejercicio del ministerio que, con demasiada frecuencia, responde a ideologías que promueven la competencia o la sustitución del ministerio ordenado -en definitiva, a la lucha por el poder-, se debería discernir y promover aquellos ministerios que el Espíritu suscite hoy para el bien de la Iglesia. Una Iglesia de la escucha, que pide a Dios los dones y ministerios necesarios para su existencia y aprende a reconocerlos en la vida concreta del pueblo de Dios. A mantener esta senda pueden ayudarnos las exhortaciones de los últimos papas, tanto Evangelii nuntiandi, Christifideles laici o Evangelii gaudium. Pero estas corren el riesgo de convertirse en letra muerta hasta que los obispos, como pastores del pueblo a ellos confiado, con la conciencia de ejercer la potestad «de juzgar y de regular todo lo que pertenece al campo del culto y del apostolado» (LG 27), tomen la decisión (parresía) de promover los dones, los carismas, las vocaciones que el Espíritu suscita en su Iglesia y, juntos, con Pedro y bajo su autoridad, disciernan «según la diversidad de ministerios». A partir de aquí se podrá volver a hablar de una «Iglesia toda ella ministerial». 